\title{
How to capture wild passerine species to study baseline corticosterone levels
}

\author{
Frédéric Angelier - Christopher M. Tonra • \\ Rebecca L. Holberton · Peter P. Marra
}

Received: 7 April 2009/Revised: 29 September 2009/Accepted: 26 October 2009/Published online: 13 November 2009

(C) The Author(s) 2009. This article is published with open access at Springerlink.com

\begin{abstract}
Baseline corticosterone levels have been suggested to be an effective tool to assess and monitor the health status of individuals and populations of wild birds. However, measuring baseline corticosterone levels in the field is difficult because the capture protocol may affect rates of corticosterone secretion. In passerine birds, two methods of capture are widely used: (1) passive netting consisting of monitoring mist-nets frequently to check if a bird has been caught; and (2) target netting consisting of installing a conspecific decoy and/or playing a tape-recorded conspecific song in the vicinity of a mist-net until the territorial bird is captured. Our objective here was to determine whether these methods of capture are effective at achieving non-disturbed baseline corticosterone levels in American Redstarts (Setophaga ruticilla). We found that passive netting was associated with elevated corticosterone levels, suggesting that hanging in a net for several minutes activates the HPA axis and, thus, elicits an adreno-cortical stress response. In contrast, target netting was not associated with an increase in corticosterone levels, regardless of the length of time between when the target bird first
\end{abstract}

Communicated by C. G. Guglielmo.

F. Angelier · P. P. Marra

Smithsonian Migratory Bird Center, National Zoological Park,

3001 Connecticut Avenue NW, Washington, DC 20008, USA

C. M. Tonra · R. L. Holberton

Laboratory of Avian Biology, Department of Biological Science,

University of Maine, Orono, ME 04469, USA

Present Address:

F. Angelier $(\square)$

Department of Neurobiology, Physiology and Behavior,

University of California, Davis, CA 95616, USA

e-mail: fangelier@ucdavis.edu approached the net and when it was captured. Therefore, we suggest that researchers interested in estimated baseline corticosterone in this species use target netting and not passive netting.

Keywords Corticosterone - Capture - Stress · Field endocrinology

\section{Introduction}

During the last decade, the use of glucocorticosteroid levels has been suggested as a useful and relevant tool to monitor the health status of individuals and populations in the wild (Cockrem 2006; Wikelski and Cooke 2006; but see Bonier et al. 2009). Indeed, corticosterone levels (the primary glucocorticosteroid in birds) often increase in response to energetic constraints and acute stressors and this rise is thought to promote behavioral and physiological adjustments that allow the individual to cope with these perturbations before becoming compromised (the concept of allostasis; McEwen and Wingfield 2003; Landys et al. 2006). Therefore, circulating corticosterone levels are likely to provide some information regarding the environmental situations and the stressors (acute or chronic) that individuals have to cope with (Wingfield et al. 1998; Landys et al. 2006; Bonier et al. 2009).

To confirm the relevancy of this endocrine tool in conservation, many studies have aimed to understand how reliably corticosterone levels can reflect environmental conditions and anthropogenic disturbance in wild vertebrates (Wasser et al. 1997; Marra and Holberton 1998; Cash and Hoberton 2005; Walker et al. 2006; Angelier et al. 2007; Jenni-Eiermann et al. 2008; Thiel et al. 2008; Bonier et al. 2009). Although chronic changes in 
corticosterone are informative regarding perturbations to environment, measuring corticosterone in the field is often difficult because it requires two steps (capturing the animal and collecting its blood), which are perceived as acute stressors, and thus, induce rapid and important changes in corticosterone levels (Wingfield et al. 1998). Therefore, blood samples collected beyond a few minutes after capture can represent an inaccurate measure of pre-handling baseline corticosterone levels. In this case, they may not mirror the environmental situation faced by an individual, but rather be its response to the acute stressor of capture and handling (Wingfield et al. 1982; Romero and Romero 2002; Romero and Reed 2005). Unfortunately, in most species and under most conditions, corticosterone levels rise after only a few minutes of exposure to a stressor. Therefore, to acquire unbiased corticosterone levels (baseline corticosterone levels), the birds must be sampled for blood quickly after capture (Wingfield et al. 1982; Schoech et al. 1999; Romero and Reed 2005; Müller et al. 2006). However, the method of capture itself can still be an acute stressor and, thus, can affect corticosterone levels (Romero and Romero 2002; Lynn and Porter 2008). In this study, we aimed to understand whether corticosterone levels are affected by two widely used methods of capture in a passerine species.

In many passerine species and during several specific life-history stages, it is impossible to use some capture methods to catch individuals (traps or others; Silverin 1998; Quillfeldt et al. 2007; Becker et al. 2006; Arnold et al. 2008), and consequently, birds are usually captured by using two alternative methods. First, birds can be captured by 'target netting' when they are territorial and responsive to a simulated territorial intrusion (STI; Holmes et al. 1989; Goymann et al. 2007). Second, birds can be captured by 'passive netting', which consists of setting up mist-nets in the locations where birds are most likely to forage or move, and then waiting for the birds to fly into the net. Sometimes, researchers diligently monitor the mist-net and are, therefore, often able to extract the bird from the net as soon as it is caught (called hereafter 'permanently monitored passive netting'). Although permanently monitored passive netting allows for reliable assessment of baseline corticosterone levels, this method can only be conducted on one focal individual at a time, is relatively labor-intensive, and can limit one's ability to catch a sufficient sample size of birds (Lynn and Porter 2008). To increase the probability of capturing multiple birds when passive netting, several mist-nets are usually set up at various locations and then monitored at regular and short time intervals to check if a bird has been captured (called hereafter 'frequently monitored passive netting'). In this case, birds are likely to hang in a mist net for several minutes prior to handling, and this may make this method inappropriate for measuring baseline corticosterone levels if birds perceive this restraint in the net as an acute stressor (Marra et al. 1995; Romero and Romero 2002).

Although target netting is definitely appropriate for some studies, it may not always provide reliable baseline corticosterone levels (Landys et al. 2007). Indeed, the presence of a conspecific decoy may be perceived as an acute stressor for a territorial bird and, thus, activate its hypothalamo-ptuitary-adrenal (HPA) axis. Aggressive interactions can be life-threatening, and the presence of a competing conspecific may also result in the loss of territory or mate. Therefore, individuals may elicit an adrenocortical stress response to adjust their physiology and their behavior to the presence of a conspecific intruder (Wingfield et al. 1998; Landys et al. 2006). Circulating corticosterone levels would increase in response to a prolonged STI and not reflect baseline levels even if the bird is sampled for blood quickly after having been caught in the net (Van Duyse et al. 2004; Landys et al. 2007). Alternatively, STI may not represent an acute stressor for a bird, especially if this intrusion is very short or does not threaten the individual and, therefore, is unlikely to entail survival costs (Harding and Follett 1979; Wingfield 1985; Silverin 1998).

Several studies have investigated the influence of a STI on corticosterone values, but often report conflicting results (Harding and Follett 1979; Wingfield 1985; Wingfield and Lewis 1993; Wingfield and Hahn 1994; Sorenson et al. 1997; Silverin 1998; Astheimer et al. 2000; Van Duyse et al. 2004; Landys et al. 2007). Moreover, the influence of passive netting on corticosterone levels has, to our knowledge, only been reported in a few species (Silverin 1998; Romero and Romero 2002). Here, we set out to determine whether passive netting and target netting differentially influence baseline corticosterone levels in an intensively studied passerine species, the American Redstart (Setophaga ruticilla), during the non-breeding period. Redstarts were captured either by frequently monitored passive netting or by target netting. Moreover, several Redstarts were also captured by permanently monitored passive netting in order to assess baseline corticosterone levels with almost certainty for some birds (Romero and Romero 2002; Wilson and Holberton 2004).

\section{Methods}

Birds and study area

Our field study was carried out in 2008 from 5 February to 27 April at the Font Hill Nature Reserve, $13 \mathrm{~km}$ west of Black River, St. Elizabeth Parish, Jamaica. The American Redstart is a small migratory passerine bird that breeds in 
North America and overwinters in the Caribbean and Central America. American Redstarts begin arriving in Jamaica and establishing non-breeding territories in midSeptember, and remain on those territories for 6-7 months until they depart on spring migration in April through midMay. During this non-breeding period, Redstarts of both sexes are territorial and occur in a variety of habitat types that vary in suitability (see Marra and Holberton 1998; Marra and Holmes 2001; Studds and Marra 2007). In this study, 104 American Redstarts-83 females and 21 males-were captured and sampled for corticosterone in mangroves and scrubs during this period to test the relevancy of different methods of capture to assess baseline corticosterone levels. After capture and blood sampling, birds were released on their territories.

\section{Capture methods}

Redstarts were caught by using either target netting $(n=27)$, frequently monitored passive netting $(n=69)$, or permanently monitored passive netting $(n=8)$. After capture and blood sampling, birds were banded with an aluminum band and a unique combination of color bands for individual recognition. All these methods of capture were used over the whole study period and in both habitats and with both sexes. Moreover, each method of capture was as used in one habitat as in another $\left(\chi^{2}=1.73, d f=3\right.$, $P=0.629$ ).

Target netting consisted of using an STI to capture a territorial bird (Wingfield 1985; Holmes et al. 1989; Goymann et al. 2007). A stuffed decoy of an adult male American Redstart was placed in the center of the territory of a Redstart and accompanied by a playback of songs and chips broadcast from an mp3 player (I-Pod Nano; Apple) through a speaker placed alongside the decoy. The decoy and speaker were placed in the center and at the base of a mist-net. In this study, we monitored the duration of the STI process until the bird was caught in the mist-net (called hereafter 'STI duration', range: $40 \mathrm{~s}$ to $15 \mathrm{~min}$, average: $6.35 \mathrm{~min}$ ). At capture, the bird was immediately extracted from the mist-net and blood was collected as quickly as possible (range 2-6 min). The duration of this blood sampling process was also monitored (called hereafter 'blood sampling duration') starting from the time when the bird was hitting the net to the end of the blood sampling process.

Frequently monitored passive netting consists of setting up several mist-nets in the locations where birds are the most likely to forage or move, and then waiting for the birds to fly into the net. In this study, we set up between 4 and 12 mist-nests in several Redstart territories and then monitored the nets regularly to check if a bird was caught. Although, for practical and logistical reasons, we did not monitor the exact interval between two checks of a given mist-net, we monitored whether a net was checked at a high frequency (interval of 2-15 min between two net checks) or a low frequency (interval of 15-25 min between two net checks). After its discovery in a mist-net, the bird was immediately extracted from the net and blood was collected as quickly as possible (range 1-6 min). The duration of this blood sampling process was monitored ('blood sampling duration') starting from the time when the bird was discovered in the net to the end of the blood sampling process.

In addition, eight Redstarts were caught by permanently monitored passive netting. We set up from 1 to 3 mist-nets in the territory of a Redstart and these mist-nets were then monitored permanently until the bird hit one of the mistnets. Then, the bird was extracted and bled within $3 \mathrm{~min}$ $30 \mathrm{~s}$ (maximum) of capture. For these birds, baseline corticosterone levels were therefore assessed with certainty (Wingfield et al. 1982; Romero and Reed 2005).

Blood sampling and hormone assay

We collected blood from the alar wing vein using a 27-gauge needle and heparinized microcapillary tubes $(50-100 \mu \mathrm{l})$. Blood samples were stored at $4{ }^{\circ} \mathrm{C}$ for up to $6 \mathrm{~h}$ until centrifuged for $10 \mathrm{~min}$ at $10,000 \mathrm{~g}$. Plasma was collected and then stored at $-20^{\circ} \mathrm{C}$ until analyzed for corticosterone concentration by radioimmunoassay at the laboratory of Avian Biology at the University of Maine, USA, as previously described (Cash and Holberton 1999).

\section{Statistical analyses}

All analyses were performed with SAS statistical software (v. 9.01; SAS Institute). For all variables tested, normality assumptions were checked by running the Shapiro-Wilkes test for normality. There were no indications that normality assumptions were violated. Preliminary analyses showed that baseline corticosterone levels did not vary with date of sampling or habitat (mangrove vs logwood scrub) whatever the method of capture ( $P>0.25$ in all cases). In addition, baseline corticosterone levels and the adrenocortical response to stress have been reported not to vary between sexes in Redstarts (Marra and Holberton 1998) and we did not find any difference in baseline corticosterone levels between sexes in our study (Student's test, $t=-1.84$, $P=0.12$ ). Thus, data from both sexes and habitats were pooled for further analyses.

First, we tested for the influence of capture method on corticosterone levels by using a GLM (dependent variable: corticosterone levels; independent variable: method of capture). In this analysis, the method of capture is a four class factor (permanently monitored passive netting, target 
netting, frequently monitored passive netting at a high frequency of net checking, frequently monitored passive netting at a low frequency of net checking). Because our aim was to test whether frequently monitored passive netting and target netting were appropriate to assess baseline corticosterone level, we only considered the birds that were bled within 3 min $30 \mathrm{~s}$ (Romero and Romero 2002; F. Angelier et al., unpublished results) to assess baseline corticosterone levels in Redstarts for this analysis (total $n=76$; i.e., permanently monitored passive netting, $n=7$; target netting, $n=19$; frequently monitored passive netting at a low frequency of net checking, $n=29$; frequently monitored passive netting at a low frequency of net checking, $n=21$ ). Second, we tested whether a STI affects corticosterone levels in Redstarts. Specifically, we tested for the influence of the STI duration on corticosterone levels by using regression analysis (dependent variable: corticosterone levels; independent variable: STI duration). For this analysis, we used the birds that were captured by target netting, but also the birds that were captured by permanently monitored passive netting (playback duration was logically considered to be 0 for these birds). Because our aim was to test whether the duration of the STI has an influence on baseline corticosterone levels, birds that were bled more than $3 \mathrm{~min} 30 \mathrm{~s}$ after capture were not included in this analysis $(n=26)$. Finally, we tested the influence of blood sampling duration on corticosterone levels. Because the influence of blood sampling duration on corticosterone level may differ with the method of capture, we included the method of capture as an independent factor in our model (GLM; dependent variable: corticosterone levels; independent variables: method of capture, blood sampling duration and their interaction). In this analysis, the method of capture is a three class factor (target netting, frequently monitored passive netting at a high frequency of net checking, frequently monitored passive netting at a low frequency of net checking). We did not include the birds that were caught by permanently monitored passive netting in this analysis (final sample size: $n=96$ ) because all these birds were bled very quickly after capture (within $3 \mathrm{~min} 30 \mathrm{~s}$ ) and reflect baseline corticosterone levels. They were therefore inappropriate to investigate the influence of blood sampling duration on circulating corticosterone levels.

\section{Results}

Corticosterone levels were significantly affected by the method of capture (GLM, $F_{3,72}=12.22, \quad P<0.001$; Fig. 1). Specifically, corticosterone levels of birds caught by permanently monitored passive netting were significantly lower than those of birds caught by frequently

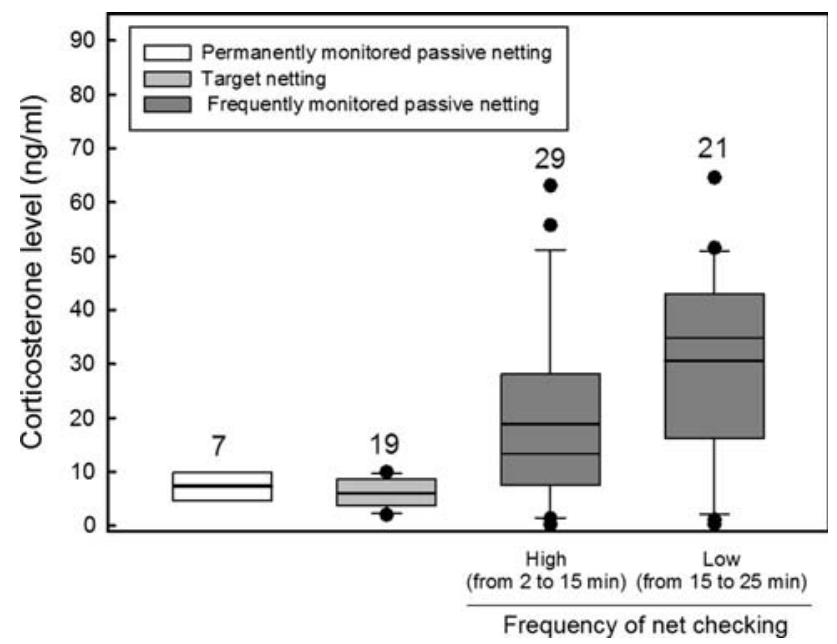

Fig. 1 Effect of the method of capture on corticosterone levels in non-breeding American Redstarts (Setophaga ruticilla). All the birds were sampled for blood within $3 \mathrm{~min} 30 \mathrm{~s}$ of discovery/capture in the mist-net. Box and whisker plots are used to represent the data: the bottom and top of the box are the lower and upper quartiles, respectively. The thin and thick bands represent respectively the median and the mean. The ends of the whiskers represent the 5th and 95th percentiles. The dots represent some outliers and the number above each box and whisker plot represents the sample size for each group

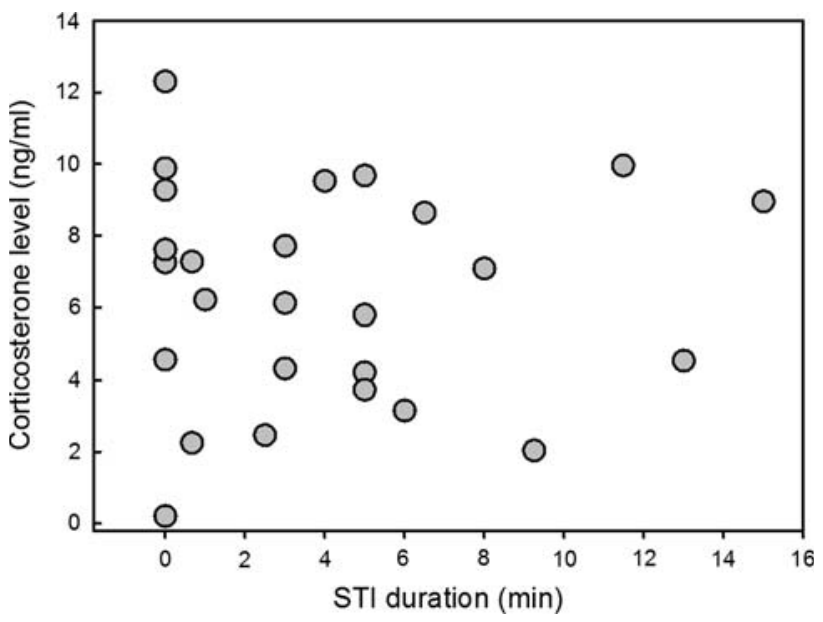

Fig. 2 Influence of the duration of the target netting process (i.e., a simulated territorial intrusion, STI) on corticosterone levels. All the birds were sampled for blood within $3 \mathrm{~min} 30 \mathrm{~s}$ of capture in the mistnet

monitored passive netting, whatever the frequency of net checking (high frequency: $\chi^{2}=4.00, P=0.045$; low frequency: $\chi^{2}=15.15, P<0.001$; Fig. 1). In contrast, corticosterone levels of birds caught by target netting did not significantly differ from those of birds caught by permanently monitored passive netting $\left(\chi^{2}=0.05\right.$, $P=0.829$; Fig. 1). Moreover, the duration of the STI did not affect corticosterone levels when birds were caught by 
target netting (regression: $F_{1,24}=0.014, \quad P=0.906$; $r$-square $<0.01$; Fig. 2).

Blood sampling duration and the method of capture had highly significant effects on corticosterone levels of American Redstarts (blood sampling duration: $F_{1,90}=9.12, P=0.003$, method of capture: $F_{2,90}=7.27$, $P=0.001$ ). Moreover, we found a significant effect of the interaction 'blood sampling duration $\times$ method of capture' $\left(F_{2,90}=3.40, \quad P=0.037\right)$. Specifically, corticosterone levels were positively correlated with blood sampling duration for the birds that were caught by target netting (parameter estimates, $\chi^{2}=9.35, P=0.002$; Fig. 3), but not for birds caught by frequently monitored passive netting whatever the frequency of net checking (parameter estimates, high frequency: $\chi^{2}=2.08, P=0.150$; low frequency: $\chi^{2}<0.01, P=0.950$; Fig. 3 ).

\section{Discussion}

Passive netting

In this study, we investigated the influence of frequently monitored passive netting on corticosterone levels by comparing corticosterone levels of birds that were sampled immediately after they hit the net (baseline corticosterone levels) with those of birds that have spent either up to $15 \mathrm{~min}$ or up to $25 \mathrm{~min}$ in the net before being sampled (frequently monitored passive netting). We showed that corticosterone levels respectively increased by an average of 115 and $220 \%$ when Redstarts spent up to 15 and $25 \mathrm{~min}$ in the net before being sampled for corticosterone, demonstrating that corticosterone levels increased with the time spent in the net. Therefore, we are confident that being caught in the net activates the HPA axis and that even a few minutes in the net can result in an increase in corticosterone secretion as previously reported in House Sparrows (Passer domesticus), White-crowned Sparrows (Zonotrichia sp.), and Pied Flycatchers (Ficedula hypoleuca) (Silverin 1998; Romero and Romero 2002). Interestingly, we found a large variance in corticosterone levels when birds were captured by frequently monitored passive netting, at either high or a low frequency, whereas we found a low variance in corticosterone levels when birds were captured by target netting and permanently monitored passive netting (Fig. 1). This large variance probably results from various time of restraint in the mist-net, but also from a high variability in the sensitivity of the HPA axis to stress between individuals (Cockrem and Silverin 2002). Some birds may have dramatically increased their corticosterone secretion after having been caught in the net, whereas others may have only slightly increased this secretion. This interpretation is supported by the fact that
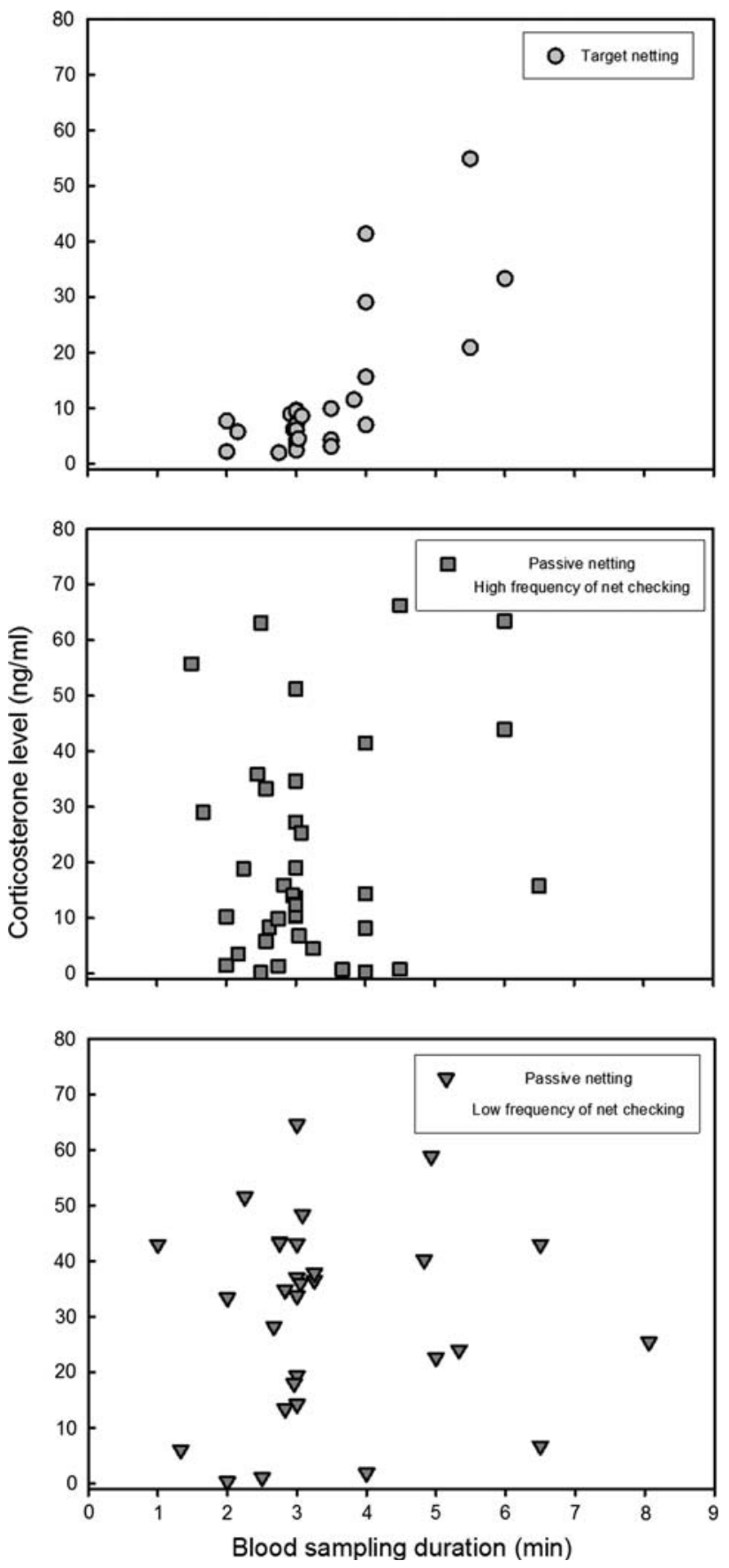

Fig. 3 Influence of the blood sampling duration on corticosterone levels for each method of capture. The time elapsed between capture-when the bird hit the net-and the start of the blood sampling procedure was respectively $0 \mathrm{~min}$ for birds caught by target netting, between 0 and $15 \mathrm{~min}$ for birds caught by frequently monitored passive netting at a high frequency of net checking, and between 0 and 25 min for birds caught by frequently monitored passive netting at a low frequency of net checking

the HPA sensitivity to stress differs between individuals in American Redstarts (corticosterone levels vary between 10 and $90 \mathrm{ng} / \mathrm{ml}$ after a 30-min stress protocol; Marra and Holberton 1998; Angelier et al. 2009). Indeed, using 
frequently monitored passive netting is problematic when studying baseline corticosterone levels because the stress of being entangled in a net elicits an adrenocortical stress response which varies between individuals. Therefore, this method of capture can bias the results, and field endocrinologists should rather use permanently monitored passive netting to assess baseline corticosterone levels in the field, even if it limits the number of birds that can be captured in a given period of time (Lynn and Porter 2008).

\section{Target netting and effect of STI}

We did not find any relationship between the duration of a STI and circulating corticosterone levels in American Redstarts. Moreover, we did not find any difference in corticosterone levels between the birds caught by permanently monitored passive netting and those caught by target netting. Therefore, target netting did not elicit an HPA stress response in non-breeding Redstarts, and this method of capture is appropriate to assess baseline corticosterone levels in this species. This probably means that the presence of a conspecific is not an acute stressor for this species, at least during the non-breeding period. Accordingly, previous studies have shown that a STI does not elicit any change in corticosterone levels in several species (Harding and Follett 1979; Wingfield 1985; Wingfield and Hahn 1994; Silverin 1998). However, corticosterone levels can also be significantly and importantly affected by STIs in other species (Wingfield and Lewis 1993; Sorenson et al. 1997; Astheimer et al. 2000; Van Duyse et al. 2004; Landys et al. 2007). Therefore, the influence of the target netting method on corticosterone levels differs between species and we suggest that it may also depend on the environmental context and, possibly, on the physiological status of individuals (Schoech et al. 1999; Landys et al. 2007). In our study, the duration of the simulated territorial intrusion was not very long (max: $15 \mathrm{~min}$ ) and we cannot exclude the hypothesis that a longer STI could have resulted in a HPA stress response: one can imagine that only the prolonged presence of a rival could be perceived as a stressor by Redstarts. However, this interpretation is unlikely because a long-term STI (up to $2 \mathrm{~h}$ ) does not affect corticosterone levels in Song Sparrows (Melospiza melodia) (Wingfield 1985). Moreover, corticosterone is rapidly secreted (within $10 \mathrm{~min}$ ) in response to a STI in Blue Tits (Cyanistes caeruleus) (Landys et al. 2007). Therefore, the duration of the STI is probably not the main factor determining whether individuals elicit a HPA stress response or not. Rather, it seems that STIs represent an acute stressor for some species, but not for others. Consequently, we recommend endocrinologists to conduct pilot studies to check that target netting can be used to assess baseline corticosterone in species for which no validation has been made.
Time of blood sampling

Not surprisingly, corticosterone levels in Redstarts increased quickly after only few minutes of handling. When using target netting with an STI, measured corticosterone levels were very elevated when blood was collected from 4 to $6 \mathrm{~min}$ of handling (maximum: $54.83 \mathrm{ng} / \mathrm{ml}$ ), whereas corticosterone levels were never above $13 \mathrm{ng} / \mathrm{ml}$ when birds were sampled for blood within $3 \mathrm{~min} 30 \mathrm{~s}$ of capture. Therefore, we confirm that it is essential to collect blood very quickly after the beginning of capture and handling to monitor baseline corticosterone levels (Wingfield et al. 1982; Schoech et al. 1999; Romero and Reed 2005; Müller et al. 2006; Scriba and Goymann 2008). Interestingly, we did not find any relationship between blood sampling duration and corticosterone levels when Redstarts were captured by frequently monitored passive netting. This result could appear surprising since the increase in corticosterone level with handling duration has been reported in numerous species (Romero 2002; Bókony et al. 2009), including American Redstarts (Marra and Holberton 1998). However, this pattern only results from the fact that frequently monitored passive netting induces some important changes in corticosterone levels (Fig. 1) and creates a lot of noise in the corticosterone value data. Therefore, this last result demonstrates that the use of frequently monitored passive netting can definitely bias one's measurement of baseline corticosterone levels, but, more importantly, can mask biological relevant relationships even when they are highly significant, such as the one linking corticosterone levels and blood sampling duration (Romero and Reed 2005; Müller et al. 2006; Scriba and Goymann 2008).

\section{Conclusion}

We emphasize that collecting baseline corticosterone levels in the field is complicated because capture and handling can represent an acute stressor for birds. First, it is essential to collect blood quickly after the start of handling (Wingfield et al. 1982; Romero and Reed 2005; Müller et al. 2006). Second, we show that target netting is a relevant technique to catch Redstarts for field endocrinologists interested in baseline corticosterone levels because this technique does not elicit a HPA stress response in this species. Third, passive netting is a relevant technique to catch birds, but only if the observer can extract the bird from the net as soon as it gets caught in the net because being entangled in a net elicits a HPA stress response (Silverin 1998; Romero and Romero 2002; this study). Thus, we highlight the need to consider the method of capture when studying baseline corticosterone levels in passerines. 


\section{Zusammenfassung}

Wie die Basislevel von Corticosteron bei Sperlingsvogelarten im Freiland gemessen werden sollten: Die Bedeutung der Fangmethode

Es wurde vorgeschlagen, dass die Basislevel von Corticosteron ein effektives Werkzeug darstellen, um den Gesundheitszustand von Individuen und Populationen wildlebender Vögel abzuschätzen und zu überwachen. Es ist jedoch schwierig, Basislevel von Corticosteron im Freiland zu messen, da die Fangmethode die Raten der CorticosteronSekretion beeinflussen könnte. Bei Sperlingsvögeln werden zwei Fangmethoden häufig angewendet: (1) passiver Netzfang, bei dem Japannetze öfters kontrolliert werden, um zu überprüfen, ob ein Vogel gefangen worden ist, und (2) gezielter Netzfang, bestehend aus der Installation eines Lockvogels derselben Art und/oder dem Abspielen eines auf Band aufgenommenen Gesangs eines Artgenossen in der Nähe eines Japannetzes, bis der territoriale Vogel gefangen ist. Unser Ziel war es zu ermitteln, ob diese Fangmethoden effektiv sind, um genaue, ungestörte Corticosteron-Basislevel von Schnäpperwaldsängern (Setophaga ruticilla) zu erbringen. Wir fanden heraus, dass passiver Netzfang mit erhöhten Corticosteron-Leveln verbunden war, was darauf hindeutet, dass das Hängen im Netz für einige Minuten eine adreno-corticale Stressantwort hervorruft. Im Gegensatz dazu war gezielter Netzfang nicht mit einem Anstieg der Corticosteron-Level verbunden, unabhängig vom Zeitabstand zwischen der ersten Annäherung des Zielvogels an das Netz und seines Fangs. Daher schlagen wir vor, dass Forscher, die daran interessiert sind, Corticosteron-Basislevel bei dieser Art abzuschätzen, gezielten Netzfang und nicht passiven Netzfang anwenden.

Acknowledgments This study was supported by an NSF grant (0649679) to P.P. Marra and R.L. Holberton and an NSF grant (0717338) to P.P. Marra. We thank E. Corliss, J.L. Dowling, J.H. Junda, S.R. Sult and M.A. Thomas for their assistance in the field. We thank the Petroleum Corporation of Hill Nature Preserve, and Yvette Strong and Andrea Donaldson of the Jamaica National Environmental Planning Agency for their cooperation.

Open Access This article is distributed under the terms of the Creative Commons Attribution Noncommercial License which permits any noncommercial use, distribution, and reproduction in any medium, provided the original author(s) and source are credited.

\section{References}

Angelier F, Shaffer SA, Weimerskirch H, Chastel O (2007) Corticosterone and foraging behavior in a pelagic seabird. Physiol Biochem Zool 80:283-292

Angelier F, Holberton RL, Marra PP (2009) Does stress response predict return rate in a migratory bird species? A study of
American redstarts and their non-breeding habitat. Proc R Soc Lond B 276:3545-3551

Arnold JM, Oswald SA, Voigt CC, Palme R, Braasch A, Bauch C, Becker PH (2008) Taking the stress out of blood collection: comparison of field blood-sampling techniques for analysis of baseline corticosterone. J Avian Biol 39:588-592

Astheimer LB, Buttemer WA, Wingfield JC (2000) Corticosterone treatment has no effect on reproductive hormones or agressive bahviour in free-living male tree sparrows, Spizella arborea. Horm Behav 37:31-39

Becker PH, Voigt CC, Arnold JM, Nagel R (2006) A non-invasive technique to bleed incubating birds without trapping: a bloodsucking bug in a hollow egg. J Ornithol 47:115-118

Bókony V, Lendvai AZ, Liker A, Angelier F, Wingfield JC, Chastel O (2009) Stress response and the value of reproduction: are birds prudent parents? Am Nat 173:589-598

Bonier F, Martin PR, Moore IT, Wingfield JC (2009) Do baseline glucocorticoid levels predict fitness? Trends Ecol Evol (in press)

Cash WB, Hoberton RL (2005) Endocrine and behavioral response to a decline in habitat quality: effects of pond drying on the slider turtle, Trachemys scripta. J Exp Zool 303A:872-879

Cash WB, Holberton RL (1999) Effects of exogenous corticosterone on locomotor activity in the red-eared slider turtle, Trachemys scripta elegans. J Exp Zool 284:637-644

Cockrem JF (2006) Conservation and behavioral neuroendocrinology. Horm Behav 48:492-501

Cockrem JF, Silverin B (2002) Variation within and between birds in corticosterone responses of great tits (Parus major). Gen Comp Endocrinol 125:197-206

Goymann W, Landys MM, Wingfield JC (2007) Distinguishing seasonal androgen responses from male-male androgen responsiveness-revisiting the challenge hypothesis. Horm Behav 51:463-476

Harding CF, Follett BK (1979) Hormone changes triggered by aggression in a natural population of blackbirds. Science 203:918-920

Holmes RT, Sherry TW, Reitsma L (1989) Population structure, territoriality and overwinter survival of two migrant warblers in Jamaica. Condor 91:545-561

Jenni-Eiermann S, Glaus E, Grüebler M, Schwabl H, Jenni L (2008) Glucocorticoid response to food availability in breeding barn swallows (Hirunda rustica). Gen Comp Endocrinol 155: $558-565$

Landys MM, Ramenofsky M, Wingfield JC (2006) Actions of glucocorticoids at a seasonal baseline as compared to stressrelated levels in the regulation of periodic life processes. Gen Comp Endocrinol 148:132-149

Landys MM, Goymann W, Raess M, Slagsvold T (2007) Hormonal responses to male-male social challenges in the blue tit Cyanistes caeruleus: single-broodedness as an explanatory variable. Physiol Biochem Zool 80:228-240

Lynn SE, Porter AJ (2008) Trapping initiates stress response in breeding and non-breeding house sparrows Passer domesticus: implications for using unmonitored traps in field studies. J Avian Biol 39:87-94

Marra PP, Holberton RL (1998) Corticosterone levels as indicators of habitat quality: effects of habitat segregation in a migratory bird during the non-breeding season. Oecologia 116:284-292

Marra PP, Holmes RT (2001) Consequences of dominance mediated habitat segregation in American redstarts during the nonbreeding season. Auk 118:92-104

Marra PP, Lampe K, Tedford B (1995) An analysis of daily corticosterone profiles in two species of Zonotrichia under captive and natural conditions. Wilson Bull 107:296-304

McEwen BS, Wingfield JC (2003) The concept of allostasis in biology and biomedicine. Horm Behav 43:2-15 
Müller C, Jenni-Eiermann S, Blondel J, Perret P, Caro SP, Lambrechts M, Jenni L (2006) Effect of human presence and handling on circulating corticosterone levels in breeding blue tits (Parus caeruleus). Gen Comp Endocrinol 148:163-171

Quillfeldt P, Strange IJ, Segelbacher G, Masello JF (2007) Male and female contributions to the provisioning rates of thin-billed prions, Pachyptela belcheri, in the South Atlantic. J Ornithol 148:367-372

Romero LM (2002) Seasonal changes in plasma glucocorticoid concentrations in free-living vertebrates. Gen Comp Endocrinol 128:1-24

Romero LM, Reed JM (2005) Collecting baseline corticosterone samples in the field: is under $3 \mathrm{~min}$ good enough? Comp Biochem Physiol 140A:73-79

Romero LM, Romero RC (2002) Corticosterone responses in wild birds: the importance of rapid initial sampling. Condor 104:129135

Schoech SJ, Ketterson ED, Nolan V (1999) Exogenous testosterone and the adrenocortical response in dark-eyed juncos. Auk 116:64-72

Scriba M, Goymann W (2008) The decoy matters! Hormonal and behavioural differences in the reaction of territorial European robins towards stuffed and live decoys. Gen Comp Endocrinol 155:511-516

Silverin B (1998) Behavioural and hormonal responses of the pied flycatcher to environmental stressors. Anim Behav 55:14111420

Sorenson LG, Nolan PM, Brown AM, Derrickson SR, Monfort SL (1997) Hormonal dynamics during mate choice in the northern pintail: a test of the 'challenge hypothesis'. Anim Behav 54:1117-1133

Studds CE, Marra PP (2007) Linking fluctuations in rainfall to nonbreeding season performance in a long-distance migratory bird, Setophaga ruticilla. Clim Res 35:115-122

Thiel D, Jenni-Eiermann S, Braunisch V, Palme R, Jenni L (2008) Ski tourism affects habitat use and evokes a physiological stress response in capercaillie Tetrao urogallus: a new methodological approach. J Appl Ecol 45:845-853

Van Duyse E, Pinxten R, Darras VM, Arckens L, Eens M (2004) Opposite changes in plasma testosterone and corticosterone levels following a simulated territorial challenge in male great tits. Behavior 141:451-467

Walker BG, Boersma PD, Wingfield JC (2006) Habituation of adult magellanic penguins to human visitation as expressed through behavior and corticosterone secretion. Conserv Biol 20:146-154

Wasser SK, Bevis K, King G, Hanson E (1997) Noninvasive physiological measures of disturbance in the northern spotted owl. Conserv Biol 11:1019-1022

Wikelski M, Cooke SJ (2006) Conservation physiology. Trends Ecol Evol 21:38-46

Wilson CM, Holberton RL (2004) Individual risk versus immediate reproductive success: a basis for latitudinal differences in the adrenocortical response to stress in yellow warblers (Dendroica petechia). Auk 121:1238-1249

Wingfield JC (1985) Short-term changes in plasma levels of hormones during establishment and defense of a breeding territory in male song sparrows, Melospiza melodia. Horm Behav 19:174-187

Wingfield JC, Hahn TP (1994) Testosterone and territorial behaviour in sedentary and migratory sparrows. Anim Behav 47:77-89

Wingfield JC, Lewis DM (1993) Hormonal and behavioural responses to simulated territorial intrusion in the cooperatively breeding white-crowned sparrow weaver, Plocepasser mahali. Anim Behav 45:1-11

Wingfield JC, Smith JP, Farner DS (1982) Endocrine responses of white-crowned sparrows to environmental stress. Condor 84:399-409

Wingfield JC, Maney DL, Breuner CW, Jacobs JD, Lynn SE, Ramenofsky M, Richardson RD (1998) Ecological bases of hormone-behavior interactions: the "emergency life history stage". Am Zool 38:191-206 